\title{
INCLUSÃO DIGITAL DE PESSOAS DA TERCEIRA IDADE ATRAVÉS DA EDUCAÇÃO A DISTÂNCIA
}

\author{
Ceris Angela Paulo *** \\ Ana Vilma Tijiboy ${ }^{* * *}$
}

\begin{abstract}
Resumo
Este trabalho aborda a inclusão de pessoas da Terceira Idade no cenário da Educação a Distância com o objetivo de inseri-las, na sociedade, utilizando esse recurso como auxílio em suas vidas diárias. Apresentam-se algumas concepções de Terceira Idade e considerações sobre o que representa a tecnologia nessa fase da vida. Relata-se um Curso Básico de Informática para Pessoas da Terceira Idade em Ambiente EAD envolvendo um grupo de 8 alunos, com idade variando entre 50 a 74 anos. Considerações finais sobre o tema incluem: o ambiente EAD pode ser permeado de afeto e incentivador de valores como solidariedade, empatia, cooperação e respeito; os alunos, no ambiente virtual, parecem precisar de mais material de apoio que nas aulas presenciais; Pessoas da Terceira Idade percebem vantagens em EAD em casos em que estejam impossibilitados de assistir aulas presenciais por motivos de viagem, problemas de saúde, de tratamento médico que requerem repouso físico. Finalmente, sugere-se o oferecimento de EAD para idosos em casa asilares. Palavras-chave: Educação à distância, Terceira Idade, Inclusão digital.
\end{abstract}

\begin{abstract}
This work approaches technological inclusion of elder people in the field of distance education as a helpful tool for their lives. Several notions concerning elders and what technology means to them are considered. A basic course of Computers for Elders through Distance Education is then described, which lasted 40 hours and involved 8 students ages ranging from 50 to 74 . Some of the final considerations suggest: the Distance Education environment can be permeated of affection and it can become a mean to promote values such as empathy, solidarity, cooperation and respect; Students, in the virtual environment, seem to need more support material than in traditional classes; Elders see Distance Learning as bringing advantages to their lives in situations involving trips, lack of health, medical treatment which require physical rest. Finally, it is suggested that elders in institutional houses may be offered distance-learning opportunities. Key words: distance education, elder people, and technological inclusion.
\end{abstract}

\section{Contextualizando o Tema}

A inclusão de setores populacionais, histórica e/ou socialmente marginalizados é um tema que vem tomando maior relevância no âmbito social, político, educacional e acadêmico, tanto no cenário brasileiro como no mundial. Sabe-se que a referida exclusão ocorre com base em critérios econômicos e éticos. Poder-se-ia ir mais longe e dizer que setores populacionais são excluídos por serem considerados fracos ou "deficientes" dentro da concepção de deficiência que implica em ser menos capaz,

\footnotetext{
"* Especialista em Informática na Educação pelo CINTED-UFRGS. Professora das Faculdades de Taquara e responsável pelo projeto de Informática da Terceira Idade.E-mail:ceris@faccat.br

*”* Dra. Em Informática na Educação. Coordenadora do Setor e Apoio aos Alunos com Deficiência Visual da UFRGS. Professora do Curso de Especialização em Informática na Educação do CINTED-UFRGS e UNISC. Professora do curso de Pedagogia da UERGS. E-mail: anatiji@etcom.ufrgs.br 
improdutivo e menos cidadão (Tijiboy, 2004).

Segundo esse raciocínio, tais setores são excluídos por serem desinteressantes do ponto de vista do lucro, por serem vistos até como estorvos ou setores decadentes. Assim, ficam à margem por não produzirem bens e serviços e/ou por tampouco serem consumidores ativos numa sociedade consumista. É o caso dos indígenas, das pessoas com necessidades educacionais especiais, os meninos de rua, as pessoas da terceira idade, entre outros. Especificamente abordando-se o caso das pessoas da Terceira Idade, tal exclusão fica evidente na preparação profissional nas diversas áreas. Nos currículos dos cursos de Pedagogia, por exemplo, até recentemente não havia disciplinas que abordassem a Andragogia. Transparece, pois, que tais setores não eram pensados, consequientemente, formava-se profissionais sem o mínimo preparo para lidar com essas pessoas.

Atualmente, porém, presencia-se na sociedade uma preocupação com uma maior inclusão. Nesse contexto, algumas ações são movidas pelo interesse de mercado. Especificamente no que diz respeito às pessoas da Terceira Idade, o Brasil ainda com uma população predominantemente jovem, começa a se dar conta de que possui um contingente interessante de "velhos" e de "velhos em potencial" (pois os jovens envelhecem), que tem interesses específicos de bens e serviços de consumo. Por outro lado, convém salientar que, no movimento de inclusão, também se inserem pessoas, profissionais e entidades verdadeiramente engajadas por razões éticas, de cidadania, ou seja, por acreditarem em uma sociedade mais justa, igualitária e humana.

Finalmente, cabe ressaltar que a exclusão/inclusão hoje em dia passa também pelo acesso à tecnologia, numa sociedade revolucionada pelos grandes avanços nessa área. Em outras palavras, numa sociedade onde o maior valor é a informação o conhecimento e o saber buscar tal informação e conhecimento, em estar informado e atualizado, usar as tecnologias de informação e comunicação é fundamental para "fazer parte". Assim, no nosso entender, a inclusão social de setores populacionais excluídos passa também necessariamente pela inclusão digital.

\section{A Terceira Idade}

O termo Terceira Idade é de influência francesa e sugere que a velhice seja associada às condições de vida do idoso, que eram caracterizadas pela solidão e marginalidade. Segundo Kachar (2003), ocorreram novas práticas de lazer, férias, e serviços especiais de saúde para os aposentados, gerando, assim, um novo olhar mais sensível ou humano em relação a essa parcela da população que costuma ser excluída da sociedade. No Brasil, esse termo foi empregado inicialmente pelo SESC de São Paulo, quando criou as "Escolas Abertas para a Terceira Idade". O termo apresenta a velhice como uma nova etapa da vida, expressa pela prática de novas práticas sociais e culturais (MAZO, 2001).

Hayflick (1997) percebe o envelhecimento não como uma mera passagem de tempo, mas a manifestação de eventos biológicos que ocorrem ao longo de um período. Assim, afirma que "envelhecimento representa as perdas da função normal que ocorrem após a maturação sexual e continuam até a longevidade máxima para os membros de uma espécie" (p. 78). Para Netto (1996), o envelhecimento pode ser conceituado como um processo dinâmico e progressivo, onde há alterações morfológicas, biológicas, funcionais e químicas, que alteram progressivamente o organismo, de modo que o tornam sensível a agressões internas e externas.

Por sua vez, a Organização Mundial da Saúde (OMS), classifica o envelhecimento em quatro estágios, sendo estes: meia idade, idoso, ancião e velhice extrema, conforme pode ser visto na tabela abaixo. 
Tabela 1: Classificação do envelhecimento conforme a OMS

\begin{tabular}{c|c}
\hline Meia-idade: & 45 a 59 anos, \\
\hline Idoso: & 60 a 74 anos, \\
\hline Ancião: & 75 a 90 anos, \\
\hline Velhice extrema: & 90 anos em diante. \\
\hline
\end{tabular}

A respeito do conceito de velhice, Simões (1994) destaca que a literatura classifica, os indivíduos acima de 60 anos como idosos e participantes da Terceira Idade, porém esse marco passou para 65 anos em função, principalmente, da expectativa de vida e das tentativas legais do estabelecimento da idade para o início da aposentadoria, dentre outros motivos. Já Mazo (2001) revela que a OMS considera idoso todo o indivíduo com 65 anos de idade ou mais, que reside em países desenvolvidos e, com 60 anos ou mais, os residentes em países subdesenvolvidos.

Uma característica importante levantada pela gerontóloga Raso (2004) é que as pessoas da Terceira Idade costumam ter medo do novo e do desconhecido e, muitas vezes, precisam do incentivo da família para começar algo novo em termos de lazer, estudos, ocupação em geral.

Fazendo uma retrospectiva histórica na sociedade ocidental sobre o que significa velhice, observa-se que, por muito tempo, esse conceito foi sinônimo de estar à margem, abrangendo preponderantemente aspectos negativos, uma fase da vida de poucas atividades e opções. Nota-se, porém, que esse conceito começa a mudar, passando-se a perceber essa fase da vida como anos da vida adulta na qual a pessoa conta com um leque ainda grande de possibilidades e realizações pessoais.

Apesar dessa mudança parcial de paradigmas, no Brasil e na América Latina de forma geral, ainda vivemos, em uma sociedade excludente. $\mathrm{O}$ idoso pertence a uma das classes excluídas, veja-se a criação de um estatuto específico para ele no sentido de garantir-lhe os direitos mais óbvios, como: lugar em filas, passagens, previdências, entre outros. Quando os setores populacionais convivem em igualdade ou harmonia com os demais, não há necessidade de se criar legislação especial.

\section{A Tecnologia nesta Idade da Vida}

Se por um lado, as novas gerações apresentam familiaridade com o uso das inovações tecnológicas que surgem aceleradamente as gerações mais velhas, dos idosos, por sua vez, encontram-se no extremo oposto, sentindo-se no meio de um "bombardeio tecnológico" que lhes causa estranheza, medo e/ou receio. Essa geração sente-se analfabeta diante das novas tecnologias, revelando dificuldades em entender a nova linguagem e em lidar com os avanços tecnológicos, até mesmo em questões básicas com eletrodomésticos, celulares e os caixas eletrônicos instalados nos bancos (KACHAR, 2003).

As pessoas acima de 50 anos, por exemplo, apesar de possuírem um acúmulo de experiências, que só o viver propicia e, apesar de ainda estarem trabalhando, costumam sofrer preconceitos no local de trabalho no que diz respeito a sua eficiência num mundo tecnológico, pois a relação com a tecnologia é vista como um indicador de eficiência, portanto a sua é posta em dúvida. Esse preconceito e a pressão social e profissional para que pessoas mais velhas se apropriem das novas tecnologias como os mais jovens, faz com que algumas delas entrem em um novo movimento rumo a uma maior familiarização tecnológica, como constata Kachar (2003). 
Nesse contexto, apesar da existência de sentimentos de receio e medo do desconhecido e ao que julgam ser de "outros tempos", pessoas da Terceira Idade saem em busca de cursos. Alguns, também para poderem auxiliar seus netos e filhos nas atividades diárias. Outros, por desejarem estar bem informados e atuantes, pois ao contrário do que muitos pensam, a hidroginástica, dança de salão, trabalhos na comunidade como voluntários não são mais os únicos programas ou atividades que lhes interessam. A informática representa para essas pessoas também um recurso contra o tédio e a alienação.

Nessa mesma direção, acreditamos que a pessoa da Terceira Idade pode tornarse um aprendiz virtual, como qualquer outra pessoa das demais faixas etárias, beneficiando-se de educação continuada, educação a distância, do bem estar e do estímulo mental que o aprender proporciona. Dentro dessa visão, a tecnologia pode possibilitar essas pessoas a estarem mais integradas em uma comunidade eletrônica ampla; colocando-as em contato com parentes, amigos e outros indivíduos num ambiente virtual de troca de idéias e informações, aprendendo junto e reduzindo o isolamento por meio da experiência comunitária, como proposto por King (apud KACHAR, 2003).

Quanto às especificidades da interação de pessoas de Terceira Idade com informática, diz nos Baldi (apud KACHAR, 2003) que grupos de idosos que demonstram interesse em aprender a usar o computador necessitam do dobro do tempo dos adolescentes. Acabaram apresentando atitudes de aproximação e interesse em relação ao computador, vindos de experiências positivas na aprendizagem e domínio da máquina. Essas mudanças de atitudes poderão ocorrer em decorrência destes se sentirem: mais familiarizados com a terminologia e a linguagem do computador; menos excluídos dos progressos tecnológicos da sociedade; menos apreensivos sobre o uso do computador e mais confiantes nas próprias habilidades para entender um computador.

No que diz respeito às vantagens da apropriação da informática por parte de alunos da Terceira Idade, Kachar (2003) chama a atenção para o fato de que, no ambiente educacional, o aluno da Terceira Idade, tem a possibilidade de demonstrar seu potencial de produção, re-construir sua auto-imagem e imagem pública, exercitando a cidadania.

É interessante salientar que, ao se procurar por cursos de informática destinados à Terceira Idade, o que geralmente se encontra no mercado são cursos que não levam em conta as especificidades dos aprendizes. Dessa forma, ensina-se Word, Excel, Internet e Power Point tendo o domínio destas ferramentas como o objetivo final, sem a preocupação de estas ferramentas servirem como meio para que os alunos possam desenvolver habilidades, atitudes e conhecimentos aplicados a outras áreas e, muito menos, sem ter a preocupação de contextualizar a aprendizagem, ignorando a trajetória do aluno, seus interesses particulares, vivências ricas a serem resgatadas e compartilhadas.

Igualmente, encontram-se na web, universidades abertas para a Terceira Idade que oferecem cursos básicos de informática, além de outras opções. Porém, provavelmente pelo fato das pesquisas existentes sobre o impacto da aprendizagem e a utilização do computador pela Terceira Idade serem poucas no Brasil, nota-se que esses cursos ainda não estão preocupados em utilizar uma metodologia de ensino específica para essa clientela, como dissemos anteriormente. Encontra-se também na Internet, alguns cursos para Terceira Idade, mas, nenhum curso básico de informática utilizando EAD em andamento. Podemos ressaltar que existe uma pesquisa sobre: 
Envelhecimento, trabalho e educação: como aprendem trabalhadores mais velhos ${ }^{1}$. Em se tratando de curso à distância para pessoas de Terceira Idade, pode-se citar um projeto na Universidade de Passo Fundo-RS que está em fase de estudos ${ }^{2}$.

Algumas experiências já realizadas sugerem que a informática pode estimular a socialização, não substituindo a presença humana, mas podendo ser mais um paliativo para a solidão. Constata-se, paralelamente, que os sites dedicados à Terceira Idade ainda enfatizam o paradigma antigo. Isto é abordam essa fase da vida apenas como sinônimo de decadência e pouco estimulam as possibilidades existentes.

Após a constatação de inexistência de cursos através de ambientes de EAD e das ainda incipientes ações envolvendo informática com pessoas da Terceira Idade e, convencidos de que a inclusão digital é uma estratégia importante no movimento maior de inclusão social de qualquer setor excluído, foi montada a experiência aqui relatada sem antes, no entanto, trazer algumas concepções importantes sobre EAD.

\section{Educação à Distância}

Uma das questões primordiais na área de Educação à Distância é a discussão que existe em torno dos termos "Educação a Distância" e "Ensino a Distância". A este respeito, Franco (2003) coloca-nos que há alguns autores mais pragmáticos, que defendem que a EAD, estaria voltada a uma prática muito utilizada há tempos atrás, o treinamento, podendo:

.... servir para uma instrução mais rápida e objetiva. Neste sentido defendem o uso de procedimentos do tipo instrução programada, que garantiria a fixação dos conteúdos que precisam ser repassados aos alunos. Estes são os que sucumbem à tentação de transformar a Educação a Distância em uma prática de 'ensino a distância (p. 7).

Moran (2004), por sua vez, propõe que se entenda a Educação a distância como:

Educação a distância é o processo de ensinoaprendizagem, mediado por tecnologias, onde professores e alunos estão separados espacial e/ou temporalmente. É ensino/aprendizagem onde professores e alunos não estão normalmente juntos, fisicamente, mas podem estar conectados, interligados por tecnologias, principalmente as telemáticas, como a Internet. Mas também podem ser utilizados o correio, o rádio, a televisão, o vídeo, o CDROM, o telefone, o fax e tecnologias semelhantes ${ }^{3}$.

Na expressão "ensino à distância" a ênfase é dada ao papel do professor (como alguém que ensina à distância). Preferimos a palavra "educação" que é mais abrangente.

Outros autores, segundo Franco (2003), defendem que a EAD seja usada para a mera instrução.

A EAD pode servir para uma instrução mais rápida e objetiva. Neste sentido defendem o uso de procedimentos do tipo instrução programada, que garantiria a fixação dos conteúdos que precisam ser repassados aos alunos. Estes

\footnotetext{
${ }^{1}$ Equipe de pesquisa/ano de 2002: Johannes Doll (coordenador), Caroline Stumpf, Ceris A. Paulo, Viviane Loeser, Ana C. Selmi, Anne Ramos.

2 BOTH, Agostinho. A Universidade de Passo Fundo e seus caminhos nas ciências do envelhecimento. Revista Brasileira de Ciências do Envelhecimento Humano, Passo Fundo/RS, V. I, n. 1, p.11-22, jan.-jun. 2004.

${ }^{3}$ Encontra-se no endereço http://www.eca.usp.br/prof/moran/dist.htm acessado em 19 nov. 2004.

V. $3 \mathrm{~N}^{\circ} 1$, Maio, 2005
} 
são os que sucumbem à tentação de transformar a Educação a Distância em uma prática de "ensino a distância" (p. 7).

Esse mesmo autor, retoma a idéia de Piaget sobre a construção do conhecimento no sentido de que não basta apenas ter acesso a informações mas precisase passar por um processo ativo de interação, entre aquele que conhece e aquilo que é conhecido, dentro de um contexto de relações meramente cognitivas (PIAGET apud FRANCO, 2003).

Além de autores com orientação construtivista (epistemologia genética cujo representante maior é Piaget), também a teoria sócio-histórica (na qual Vygotsky é, sem dúvida, o seu maior representante) concebe a aprendizagem como um processo que inclui, necessariamente, a interdependência dos indivíduos envolvidos no processo, entre aquele que aprende, aquele que ensina e a relação entre essas pessoas. A aprendizagem, para Vygotsky (2000), possibilita o despertar dos processos internos de desenvolvimento, relacionados às funções psicológicas superiores (de natureza social, cultural e histórica). Embora se constituam duas teorias de aprendizagem e desenvolvimento diferentes, ambas são interacionistas e enfatizam, portanto, a grande relevância da interação social na aprendizagem.

Por outro lado, ainda segundo Franco (2003), alguns autores defendem que a garantia do sucesso da Educação a Distância está na motivação do aluno, pois ela proporcionaria a aprendizagem. Sabe-se, também, que o processo educacional não é um processo solitário e que não depende exclusivamente do aluno, mas das relações cognitivas e as sociais.

Portanto, a Educação a Distância possibilita a educação às pessoas mais distantes e às mais próximas geograficamente, numa interação entre sujeitos que utilizam um mesmo espaço e tempo virtual na construção do seu conhecimento.

Keegan apud Nunes (2004), sumariza os elementos que considera centrais dos conceitos sobre Educação e Ensino à Distância: Separação física entre professor e aluno; Influência da organização educacional (planejamento, sistematização, plano, projeto, organização dirigida etc), que a diferencia da educação individual; Utilização de meios técnicos de comunicação, usualmente impressos, para unir o professor ao aluno e transmitir os conteúdos educativos; Previsão de uma comunicação de mão dupla, onde o estudante se beneficia de um diálogo, e da possibilidade de iniciativas de dupla via; Possibilidade de encontros ocasionais com propósitos didáticos e de socialização; e Participação de uma forma industrializada de educação, a qual, se aceita, contém o gérmen de uma radical distinção dos outros modos de desenvolvimento da função educacional.

Belloni (2003), por sua vez, apresenta o termo ou a modalidade de AAD (Aprendizagem Aberta e a Distância), que é, segundo ele, mais coerente com as transformações sociais e econômicas, e que se caracteriza principalmente pela sua flexibilidade, abertura dos sistemas e maior autonomia do educando. O fundamento desse modelo é a centralidade do aprendente no processo de aprendizagem.

$\mathrm{Na}$ definição apresentada acima, observamos que há ênfase maior nos processos de ensino (estrutura organizacional, planejamento, concepção de metodologias, produção de materiais, etc.) e pouca ou nenhuma consideração dos processos de aprendizagem (características e necessidades dos estudantes, modos e condições de estudo, níveis de motivação etc.). Assim, podemos dizer que os modelos apresentados, referem-se muito mais aos "sistemas ensinantes" do que aos "sistemas aprendentes” (CARMO apud BELLONI, 2003). 
Para Belloni (2003, p. 31), a diferença entre EAD e AA é a seguinte:

Enquanto para a EaD os parâmetros definidores essenciais são a separação professor/aluno e o uso de meios técnicos para compensar esta separação, na AA estes elementos podem estar presentes, mas não são considerados essenciais: AA se define fundamentalmente por critérios de abertura, relacionados a acesso, lugar e ritmo de estudo.

Na visão dessa autora, uma não se opõe a outra, ao contrário, é no campo da $\mathrm{EaD}$ que esse modelo de educação, aberto e flexível, encontra terreno mais fértil para se desenvolver. EaD diz respeito a uma modalidade de educação e a seus aspectos institucionais e operacionais, referindo-se, principalmente, aos sistemas "ensinantes"; enquanto AA relaciona-se mais com modos de acesso e com metodologias e estratégias de ensino e aprendizagem, ou seja, enfoca as relações entre os sistemas de ensino e os aprendentes (BELLONI, 2003).

Por outro lado, Trindade apud Belloni (2003, p. 30), relaciona os conceitos de aprendizagem aberta e à distância, colocando elementos fundamentais como: acessibilidade aos sistemas e flexibilidade do ensino:

A relação entre os conceitos de aprendizagem aberta e aprendizagem a distância é mais complexa. Aprendizagem aberta tem essencialmente dois significados: de um lado refere-se aos critérios de acesso aos sistemas educacionais ("aberta" como equivalente da idéia de remover barreiras ao livre acesso à educação); de outro lado, significa que o processo de aprendizagem deve ser, do ponto de vista do estudante, livre no tempo, no espaço e no ritmo (time-free, place-free e pace-free). Ambos os significados estão ligados com uma filosofia educacional que identifica abertura com aprendizagem centrada no estudante.

Através de desenvolvimento de pesquisas especificamente sobre o ensino/ aprendizagem de adultos, que estão centradas no estudante dando-lhe mais autonomia, a EAD apresenta-se como aliado que pretende superar os modelos tradicionais. A produção de conhecimento nessa área pode ser extremamente proveitosa para o aperfeiçoamento didático do ensino convencional (SAYERS apud BELLONI, 2003).

A experiência adquirida no campo da educação de adultos revelou que os métodos pedagógicos e didáticos para crianças e jovens não se mostram adequados para adultos: a razão disto é que o modelo pedagógico é essencialmente heterônimo, dado que a relação educativa é estabelecida por um controle externo agindo sobre o sujeito, enquanto o modelo andragógico é sobretudo "autonômico" e autodirigido. Adultos acham em si mesmos as motivações para, e as necessidades de, aprender; e o processo de aprendizagem não pode ser imposto por fontes externas independentes, nem ignorar as habilidades e competências já adquiridas e as condições de vida (situação familiar, profissão, meio social) do indivíduo (TRINDADE apud 
BELLONI, 2003, p. 30) [grifo do autor].

Ao que parece, cada vez mais os especialistas buscam inspiração para a elaboração de estratégias e métodos de ensino que realmente levem em consideração a auto-aprendizagem e a aprendizagem autônoma na EAD.

Os conceitos até aqui apresentados ilustram a grande gama de concepções encontradas na literatura, sobre EaD e AAD. A esse respeito, no entanto, Belloni (2003) chama a atenção para "a consolidação do conceito de aprendizagem aberta e à distância (open distance learning), em torno do qual há certa unanimidade, e a tendência da tecnologia educacional evoluir para uma concepção mais ampla de comunicação educacional” (p. 34) [grifo do autor].

\section{Curso Básico de Informática Para Pessoas na Terceira Idade Em Ambiente EAD}

A preocupação por utilizar as novas tecnologias em prol da inclusão digital de setores excluídos, fez surgir em nós a seguinte reflexão: como poderíamos dar às pessoas de Terceira Idade oportunidades de construção e ampliação dos seus direitos à cidadania, através da utilização dos novos recursos digitais e educacionais disponíveis? Motivados em buscar algum caminho, planejamos um curso básico para pessoas da Terceira Idade em Ambiente EAD, utilizando a plataforma TELEDUC.

Também estávamos preocupadas em refletir sobre o processo de apropriação das $\mathrm{TICs}^{4}$ pelas pessoas de Terceira idade, isto é, como se comportavam ao interagir em ambiente de EAD, suas atitudes, interações, dificuldades, comentários, etc.

Entre os objetivos do curso constavam:

- Introduzir o ambiente EAD e metodologia para alunos de Terceira Idade.

- Propiciar momentos de troca sobre recursos básicos de Informática e edição de texto.

- Realizar atividades de leitura sobre a realidade da Terceira Idade no cenário da Tecnologia de Comunicação e Informação.

Os conteúdos abordados, por sua vez, foram:

- Introdução/exploração do ambiente EAD - TELEDUC.

- Conceitos básicos dos equipamentos utilizados para a aula.

- Digitação e formatação no editor de texto.

Pensar em informática para a Terceira Idade através de EAD implicou, necessariamente, em ter sempre presente que a informática é uma ferramenta que pode auxiliar na resolução de questões pertinentes ao trabalho que os aprendentes estão desenvolvendo, seja na área social ou cultural. Essa utilização devia ser prazerosa, motivada e o aluno deve ser o centro da ação, sendo a sensibilidade e a paciência elementos fundamentais por parte do professor que conduz o processo.

Levando em consideração esses aspectos, buscou-se identificar as necessidades de informação, construção do novo conhecimento do grupo, através de estratégias pedagógicas relacionadas com o dia-a-dia dos alunos. Assim, inicialmente os participantes do curso responderam um questionário, preenchendo-o diretamente no computador na aula presencial. Ao final do curso, foi solicitado aos mesmos que respondessem a uma entrevista contendo perguntas voltadas para as experiências de aprendizagem em geral e mais especificamente (escola, curso) ao curso realizado em ambiente EAD. Ambos instrumentos levantaram informações importantes para o

\footnotetext{
${ }^{4}$ Tecnologias de Informação e Comunicação.
} 
desenvolvimento do curso e para as reflexões sobre o tema em questão.

Os encontros ocorreram no período de 23/09/200 a 18/11/2004, totalizando 40 horas. Os participantes foram 8 alunos, com idade variando entre 50 a 74 anos. Cinco alunos tinham algum conhecimento de informática e um nenhum conhecimento. Dentre eles, três ainda se encontram no mercado de trabalho e os demais são aposentados.

O curso não foi totalmente à distância, incluindo também a modalidade presencial e simulação de aulas à distância, devido ao fato de alguns alunos não possuíam computador e acesso à Internet nas suas casa. Uma monitora acompanhou presencialmente, observando as reações dos alunos e suas dificuldades.

\section{Lições Aprendidas}

O presente trabalho nos permitiu realizar varias reavaliações de conceitos préestabelecidos sobre EAD utilizado por pessoas da Terceira Idade. Apesar de acreditarmos no potencial da EAD para a educação de diversos setores populacionais, tínhamos receio quanto a sua utilização com pessoas da Terceira idade, por acreditarmos que a distância física nessa fase da vida não é desejável nem aconselhável. E que estar em grupo e continuar em atividade para essas pessoas significava, necessariamente um contato presencial, do tipo olho no olho, rejeitando outro tipo de interação, entre elas a virtual. Porém, apesar destas nossas crenças, desejávamos constatar como um curso de EAD era de fato percebido, recebido e avaliado por alunos nessa faixa etária. Em outras palavras, desejávamos ouvir as pessoas diretamente envolvidas, ao invés de permanecermos com o que nos era de senso comum. Tínhamos também um certo medo de que na execução do curso, o processo pudesse se tornar mais do tipo "ensino a distancia" do que "educação a distância", algo que não desejávamos.

Pudemos perceber, porém que as tecnologias de comunicação oferecem um potencial interessante na melhoria da qualidade de vida da pessoa da Terceira Idade, provendo-a com informações e serviços externos à sua residência, podendo obter atualização em qualquer área, mesmo que o idoso se encontre em casas asilares ou com dificuldade de locomoção.

Descobrimos através do "perfil dos alunos", recurso disponível no ambiente de EAD utilizado (Teleduc) que os participantes do curso, eram na sua maioria aposentados e que costumavam participar de viagens de turismo, outros apresentavam problemas de saúde. Presenciamos, como é de se esperar em cursos de EAD com outras faixas etárias, que os nossos alunos também continuaram suas atividade normais, que no seu caso envolviam atividades sociais, viagens e indisposição física devido à realização de tratamento médico que não permitia aos alunos que saísse de suas residências. Assim, presenciamos situações reais no qual o uso de um ambiente à distância possibilitou aos alunos não ficarem prejudicados na sua aprendizagem devido à ausência física no local de realização do mesmo. Continuaram a acompanhar os colegas, as aulas, do lugar onde se encontravam e enfrentando situações inusitadas como, por exemplo, o de solicitar no total acesso à Internet.

Aprendemos que quando se disponibilizam novas experiências como a nossa, deve-se levar em consideração que o ritmo de interação com o computador é mais lento, requerendo um tempo maior para aprender. As limitações físicas e cognitivas, tornam necessário o uso de estratégias específica. Assim, é importante disponibilizar mais tempo no início de aulas presenciais para que se sintam seguros ou familiarizados com o ambiente tecnológico a essa geração que não está familiarizada com a tecnologia antes de arriscar interagir sozinhos.

Também percebemos que provavelmente por pertencerem a uma geração na qual a educação tinha como seu eixo central o professor sentem muita falta dessa figura 
presencial. Nesse sentido, a coleta de dados nos permitiu verificar que o curso agradou apesar da resistência de alguns alunos sentirem necessidade de "ver" a professora na sala de aula, ao que parece dando-lhes sensação de segurança de que receberão o auxílio que precisam.

Pudemos observar que o chat foi a ferramenta mais utilizada pelos alunos e ao que parece, segundo comentário de aluno, deixava-os à vontade, após o período inicial de adaptação a esse recurso. Depoimentos do tipo: "estou adorando esses momentos que passamos juntas aqui, estou me sentindo mais leve, mais descontraída e isso é muito bom"; "estou encantada com a nova experiência"; "D. Ceris dentro da sala de bate-papo permita-me não usar a Sra?", "é que fui ensinado desta forma e isso fica no sangue, mas como a modernidade mudou para os mais jovens, gostaria de acompanhar parece que usando vc fica mais íntima a conversa. Obrigado" deixam transparecer a aceitação do curso em modalidade de EAD por parte dos alunos.

Percebemos também que devemos ficar alertas para as especificidades dos ambientes informatizados utilizados para atividades à distancia com faixas etárias diversas. Por exemplo, pudemos notar que a sala de bate-papo que costuma ser para as gerações mais novas um dispositivo muito lento causando impaciência e reclamações, não o foi para os alunos do curso para a Terceira Idade. $O$ fator rapidez de digitação e a assincronia de diversos bate-papos não foi um fator importante com este grupo.

Em suma, a experiência prática unida à teoria permitiu-nos novos olhares para a utilização da EAD com pessoas da Terceira Idade. Percebemos que acompanhar a evolução dos tempos é uma preocupação das pessoas da Terceira Idade. Conhecer os novos recursos tecnológicos que os mais jovens utilizam e que lhes permite uma atualização nas mais diversas áreas de atuação/conhecimento, participar de Cursos de EAD pode contribuir nesse sentido. Não priva-las, portanto, de novas experiências, que na nossa percepção podem não ser compatível com sua idade, talvez tenha sido a maior lição por nós aprendida.

\section{REFERÊNCIAS BIBLIOGRAFICAS}

BELlONI, Maria Luiza. Educação a Distância. 3. ed. Campinas, S. P.: Autores Associados, 2003.

BOTH, Agostinho. A Universidade de Passo Fundo e seus caminhos nas ciências do envelhecimento. Revista Brasileira de Ciências do Envelhecimento Humano, Passo Fundo/RS, V. I, n. 1, p.11-22, jan.-jun. 2004.

FRANCO, Sérgio Roberto Kieling. Algumas reflexões sobre educação à distância. Textual, Porto Alegre, v. 1. n. 2, p. 6-11, ago. 2003.

INFORMÁTICA para terceira idade faz sucesso e é aprovada pelos alunos. Disponível em: <http://www.puc-rio.br/jornaldapuc/nov97/informatica.html> Acesso em: 18 set. 2004.

MAZO, Giovana Zarpellon; LOPES, Marize Amorin; BENEDETTI, Tania Bertoldo. Atividade física e o idoso: concepção gerontológica. Porto Alegre: Sulina, 2001.

KACHAR, Vitória (org.). Longevidade: um novo desafio para educação. São Paulo:

Cortez, 2001.

MORAN, José Manuel; MASETTO, Marcos T.; BEHRENS, Marilda Aparecida. Novas Tecnologias e Mediação Pedagógica. 5. ed. São Paulo: Papirus, 2002.

NETTO, Matheus Papaléo. Gerontologia - a velhice e o envelhecimento em visão globalizada. São Paulo: Atheneu, 1996.

NUNES, Ivônio Barros. Noções de Educação a Distância. Disponível em: 
<http://www.intelecto.net/ead_textos/ivonio1.html> Acesso em: 18 abr. 2004.

SHERRY, Lorraine. Issues in Distance Learning. Disponível em: <http://penta.ufrgs.br/edu/edu1.html> Acesso em: 11 abr. 2004.

TIJIBOY, Ana Vilma.Um Olhar Sócio-histórico sobre as Tecnologias de Informação e Comunicação na Educação Especial. FRANCO, Sérgio Roberto Kieling (org.) Informática na Educação: estudos interdisciplinares. Porto Alegre, Editora da UFRGS, 2004.

VYGOTSKY, L. S. El Desarrolho de los procesos psicológicos Superiores. Barcelona: Crítica, 2000

ZIMMERMANN, D. E. Vocabulário Contemporâneo de Psicanálise. Porto Alegre: Artmed, 2001. 